\title{
Simulation Researches on Thermal Characteristics of Vehicular In-wheel Motors
}

\author{
Fu-Xing YAO $^{\mathrm{a}}$, Zhe-Ke ZHANG ${ }^{\mathrm{b}}$ and You-Tong ZHANGc, ${ }^{*}$ \\ Beijing Institute of Technology, Beijing 100081, CHINA \\ a189010881810@126.com, b417759979@qq.com, cyoutong@bit.edu.cn \\ ${ }^{*}$ Corresponding author
}

Keywords: In-wheel Motor, Thermal Characteristics, Simulation Component, Formatting.

\begin{abstract}
The thermal characteristics of In-wheel Motor is one of the key technologies for the motors used in the New Energy Vehicles. In this paper, the thermal simulation model of in-wheel motor used for solar car was established, the thermal characteristics of In-wheel motor were analyzed by building the mass flow and heat-transfer coupling simulation model. The motor temperature field data were acquired by simulation combined with the actual work conditions. The simulation air cooling model of in-wheel motor and verification researches were carried out, which provides the basis for the further thermal design and optimization of In-wheel motor structure.
\end{abstract}

\section{Overview}

In response to the increasingly stringent environmental protection and low energy consumption challenges, electric vehicle, as the mainstream of the new energy vehicles, has been developing rapidly. Motor is one of the key components for new energy vehicles, and its technological progress has a great impact on vehicle's performance. In-wheel motor is the future direction of new energy electric vehicles development, which can not only save the car space but also achieve independent drive control. However, practical application of In-wheel motor must deal with problems like thermal stress, torque fluctuations and compact structure.

Many scholars have conducted a lot of researches regarding motor cooling. Jinxin Fan [1] etc. used the lumped thermal parameter method to analyze the thermal behavior of the motor in the actual working condition. Due to the slight increase in loss caused by temperature change, efficiency decrease is not obvious within short time. Normally we regard the temperature field and electromagnetic field as non-coupling treatment, which indicates that loss does not vary with time, or efficiency [2]. K. Farsane [3] et al. measured the temperature, flow display and velocity, pointed out the correlation between the thermal and aerodynamic conditions of the motor and modify the geometry of the motor body to significantly improve the cooling effect. Lukas Kung [4] and others, based on aerodynamics, improved the $2-15 \mathrm{MW}$ self-ventilation in aspects including stator bar and rotor inlet, which brings better cooling effect.

Despite the researches mentioned above, thermal characteristics for In-wheel motor is a problem that few people concentrated and which must be solved for real application. This paper conducted simulation research on the heat dissipation of the solar car in-wheel motor. Based on the heat dissipation model, the simulation research was carried out, and the model was also validated.

\section{The Cooling Model of Pmsm In-Wheel Motor}

The permanent magnet synchronous in-wheel motor used in this research is an external rotor structure, which is shown in Fig. 1, including the outer rotor, stator, magnet and position sensors. 


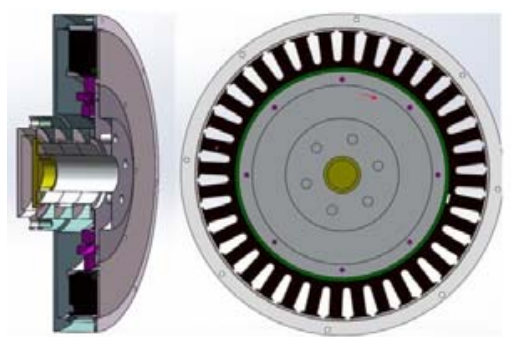

Fig. 1 The Structure of External Rotor Permanent Magnet Synchronous Motor

The heat source of the in-wheel motor mainly includes stator winding loss and stator core loss. The heating power is mainly concentrated in the stator part. Winding loss is caused by the current passing through the winding, considered as the basic copper consumption, according to Joule law:

$$
\mathrm{P}_{\mathrm{Cu}}=3 \mathrm{I}^{2} \mathrm{R}
$$

Where: $\mathrm{I}$ is the phase winding current, A; R is the phase winding resistance, $\Omega$.

$$
\mathrm{R}=\mathrm{R}_{0}\left[1+\alpha\left(\mathrm{T}-\mathrm{T}_{0}\right)\right]
$$

$\alpha$ is the resistance temperature coefficient, $\alpha=0.0039 \Omega /{ }^{\circ} \mathrm{C} ; \mathrm{R}_{0}$ is the resistance value at room temperature, $\mathrm{T}_{0}$ is the normal temperature, $\mathrm{T}$ is the working temperature.

In-wheel motor condition parameters are determined from the vehicle dynamics equation. As the vehicle's only power mechanism, motor's rated output power is supposed to balance the resistance in the car driving project, as Formula 3 shown below:

$$
\mathrm{P}_{\mathrm{N}}=\frac{1}{\eta_{\mathrm{T}}}\left(\mathrm{P}_{\mathrm{w}}+\mathrm{P}_{\mathrm{f}}\right)=\frac{1}{\eta_{\mathrm{T}}}\left(\frac{\mathrm{mgf}}{3600} \mathrm{u}_{\mathrm{a}}+\frac{\mathrm{C}_{\mathrm{D}} \mathrm{A}}{76140} \mathrm{u}_{\mathrm{a}}^{3}\right)
$$

In the above formula, $\mathrm{P}_{\mathrm{N}}$ is the rated motor power, $\mathrm{kW} ; \eta_{\mathrm{T}}$ is the transmission system efficiency parameter; $\mathrm{P}_{\mathrm{w}}$ is the air resistance power, $\mathrm{P}_{\mathrm{f}}$ is the rolling resistance power, $\mathrm{kW} ; \mathrm{m}$ is the vehicle's curb weight, $\mathrm{kg} ; \mathrm{f}$ is the rolling friction resistance coefficient; $\mathrm{C}_{\mathrm{D}}$ is the drag coefficient; $\mathrm{u}_{\mathrm{a}}$ is the cruising speed, $\mathrm{km} \cdot \mathrm{h}^{-1} ; \mathrm{A}$ is the windward area, $\mathrm{m}^{2}$.

Through calculation we can get $\mathrm{P}_{\mathrm{N}}=1.5 \mathrm{~kW}$. Considering climbing acceleration and other conditions, the parameters of the motor are determined as follows: rated voltage is $130 \mathrm{~V}$; rated power is $1.5 \mathrm{~kW}$, rated speed is $800 \mathrm{r} / \mathrm{min}$, peak torque is $40 \mathrm{~N} \cdot \mathrm{m}$.

\section{The Simulation of Motor Temperature Field}

Based on the analysis of the heating power of the permanent magnet synchronous motor and the specific geometric model, CFD simulation of flow and heat transfer coupling based on the Fluent software under rated operating conditions is given.

\section{The Coupling Model of Motor Flow and Heat Transfer}

Ignoring the small parts and the structure of the motor, the stator steel core and the coil winding are equivalent to the rotor permanent magnet, to anisotropic homogeneous material. The thermal conductivity of the motor core is $3.4 \mathrm{~W} / \mathrm{m} \cdot \mathrm{K}$, The longitudinal thermal conductivity is $40.6 \mathrm{~W} / \mathrm{m} \cdot \mathrm{K}$, the density is $7650 \mathrm{~kg} / \mathrm{m}^{3}$, The heat capacity is $502.4 \mathrm{~J} / \mathrm{kg} \cdot \mathrm{K}$; Coil winding insulation layer is only a thin layer, and the physical parameters compared to copper basically negligible. The windings are equivalent to homogeneous copper wires. The density is $8978 \mathrm{~kg} / \mathrm{m}^{3}$, the Thermal conductivity is $387.6 \mathrm{~W} / \mathrm{m} \cdot \mathrm{K}$, the Specific heat capacity is $381 \mathrm{~J} / \mathrm{kg} \cdot \mathrm{K}$; Outer rotor and intermediate shaft and other non-heating parts are equivalent to the boundary wall; equivalent parameters are shown in Table 1: 
Table 1 Equivalent parameters of motor winding core

\begin{tabular}{ccccc}
\hline & $\begin{array}{c}\text { Density } \\
\left(\mathrm{kg} / \mathrm{m}^{3}\right)\end{array}$ & $\begin{array}{c}\text { Specific Heat } \\
\text { Capacity } \\
(\mathrm{J} / \mathrm{kg} \cdot \mathrm{K})\end{array}$ & $\begin{array}{c}\text { Radial Thermal } \\
\text { Conductivity } \\
(\mathrm{W} / \mathrm{m} \cdot \mathrm{K})\end{array}$ & $\begin{array}{c}\text { Axial Thermal } \\
\text { Conductivity } \\
(\mathrm{W} / \mathrm{m} \cdot \mathrm{K})\end{array}$ \\
\hline Core material & 7650 & 502.48 & 40.6 & 3.4 \\
\hline $\begin{array}{c}\text { Winding } \\
\text { material }\end{array}$ & 8978 & 381 & & 387.6 \\
\hline
\end{tabular}

\section{Simulation Condition Setting}

Input the grid model into the Fluent software and check the grid quality. If the grid quality is poor, re-divide the grid, which is related to the heat analysis, then set k-epsilon flow model.

The thermal parameters of the motor are based on homogeneity equivalent, and the heat of the motor is to be tested by experiment. The motor is set to $1.5 \mathrm{~kW}$ and $1.1 \mathrm{~kW}$ constant power, the test data are shown in Table 2:

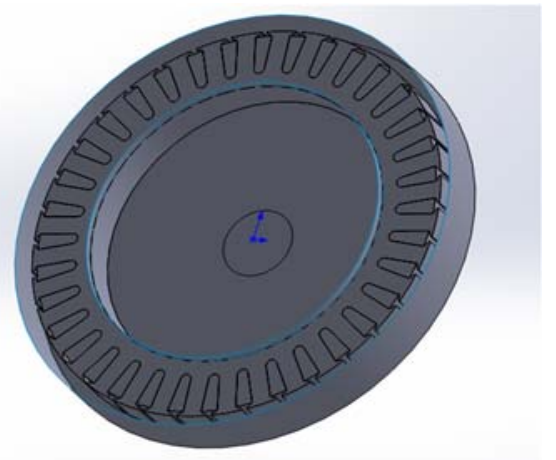

Fig. 2 Equivalent Model of Motor Structure

Table 2 The results of the motor constant power experiments

\begin{tabular}{|c|c|c|c|c|}
\hline Time $(\mathrm{s})$ & Voltage (V) & Current (A) & Voltage $(\mathrm{V})$ & Current (A) \\
\hline & \multicolumn{2}{|c|}{$1.5 \mathrm{~kW}$} & \multicolumn{2}{|c|}{$1.1 \mathrm{~kW}$} \\
\hline 0 & 126.8 & 11.3 & 126.3 & 8.3 \\
\hline 300 & 125.8 & 11.1 & 125.9 & 8.4 \\
\hline 600 & 125 & 11.3 & 125.4 & 8 \\
\hline 900 & 124.3 & 11.1 & 125 & 8.2 \\
\hline 1200 & 123.6 & 11.5 & 124.2 & 8.4 \\
\hline 1500 & 122.9 & 11.5 & 123.8 & 8.3 \\
\hline 1800 & 121.8 & 11.6 & 123.4 & 8.5 \\
\hline 2100 & 120.9 & 11.6 & 122.7 & 8.7 \\
\hline 2400 & 119.7 & 11.7 & 122.2 & 9 \\
\hline 2700 & 119.3 & 11.8 & 121.7 & 9.1 \\
\hline 3000 & 118.6 & 11.7 & 121.3 & 8.8 \\
\hline 3300 & 117.8 & 12 & 120.4 & 8.8 \\
\hline 3600 & 116.8 & 12 & 120 & 8.8 \\
\hline 3900 & 116.4 & 11.9 & 119.5 & 8.8 \\
\hline 4200 & 115.7 & 12 & 118.7 & 8.9 \\
\hline 4500 & 114.5 & 12.1 & 118.4 & 8.8 \\
\hline 4800 & 114.2 & 12 & 118 & 8.6 \\
\hline 5100 & 113.8 & 12.2 & 117.6 & 9 \\
\hline 5400 & 113.4 & 12.3 & 117 & 9 \\
\hline
\end{tabular}

$\mathrm{P}=\frac{\mathrm{T}_{\mathrm{n}}}{9550}$ 
Through the output speed and torque, the output power is calculated by Formula 4, using the input voltage and input current to calculate the output power. In qualitative analysis, all the power loss is converted into heat, increasing the motor stator temperature as thermal power:

Therefore, it can be calculated that the rated power is the total thermal power $P_{t}=120 \mathrm{~W}$, The total thermal power of the low power condition is $\mathrm{P}_{\mathrm{t}}=90 \mathrm{~W}$. Measure the two-phase resistance of the series value and then take the average. The measurement results are shown in Table 3:

Table 3 The measurement results of motor winding

\begin{tabular}{l|c|c|c}
\hline & UV Phase & VW Phase & WU Phase \\
\hline Winding resistance $(\mathrm{m} \Omega)$ & 47.4 & 46.2 & 44.7 \\
\hline
\end{tabular}

Calculated by the resistance value of single phase windings derived from data in the Table 3 , the resistance value of permanent magnet synchronous motor single-way winding is $23.05 \mathrm{~m} \Omega$, By calculation, the winding power of motor $1.5 \mathrm{~kW}$ and $1.1 \mathrm{~kW}$ are $51.1 \mathrm{~W}$ and $32.6 \mathrm{~W}$. The corresponding difference is the core's thermal power, $68.9 \mathrm{~W}$ and $57.4 \mathrm{~W}$ respectively, Dividing above-mentioned calorific value by the core and the winding volume, the heating power per unit volume winding and core is $106085.5 \mathrm{~W} / \mathrm{m}^{3}$ and $58792.3 \mathrm{~W} / \mathrm{m}^{3}$, respectively.

Set the material parameters in the Fluent software, using transient simulation, with the time set as 5400s. To avoid excessive load steps, each load step is set to $300 \mathrm{~s}$, a total of 18 load steps, corresponding to 18 files. Since the experimental process is actually using the observed highest temperature of thermal imager every $5 \mathrm{~min}$, respectively, the highest and lowest temperature are respectively extracted from the results. In order to compare the experimental results, set two conditions respectively; one is the natural convection, which has a constant power of $1.5 \mathrm{~kW}$ and $1.1 \mathrm{~kW}$ constant power work, and the other is $1.5 \mathrm{~kW}$ forced convection heat transfer. Set the boundary conditions in the Boundary Conditions panel. To compare with the experiment, the inlet temperatures are set at $18.3^{\circ} \mathrm{C}$ and $17.5^{\circ} \mathrm{C}$ respectively. The wind speed of the cooling fan is $2.5 \mathrm{~m} / \mathrm{s}$, that is, the entrance wind speed is $2.5 \mathrm{~m} / \mathrm{s}$, and the outlet type is Outflow. Solid-liquid interface for the coupling interface is set to Coupled. Select the entrance initialization interface Initialize, and the other are default settings.

\section{Simulation Results Analysis}

The calculation results from the Fluent were processed by using CFD-POST. For two kinds of natural convection conditions, the final temperature field distribution is basically the same, only with different specific temperature values. The final motor stator and winding temperature field is shown in the Fig. 3, the motor winding temperature is the highest, temperature decreases from the tooth to the yoke of the stator core, showing a temperature gradient changes. The intuitive results also meet the basic theory of physics.

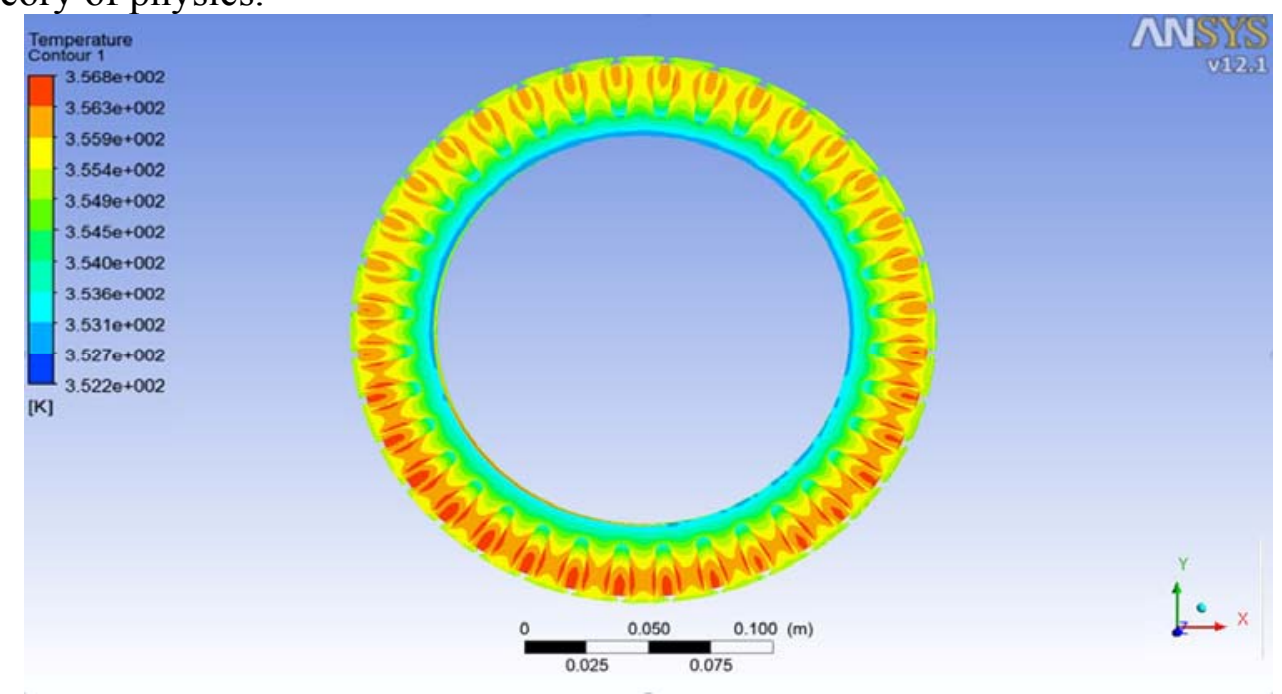

Fig. 3 Temperature Field Distribution of Natural Convection 
Change the forced convection boundary condition to calculate the forced convection heat transfer condition. The final temperature distribution of the motor stator and winding temperature is shown in Fig. 4. It can be seen from the Fig. that the temperature field of the forced convection is not very different from the natural convection, because the heat of the motor windings and the stator is large and the specific heat capacity of the gas is small and will not have a great influence on the temperature field distribution. The results of the actual thermal imager are consistent. The motor winding temperature is the highest. Temperature decreases from the tooth to the yoke of the stator core, showing a temperature gradient changes. The intuitive results also meet the basic theory of physics. The highest temperature of the above simulation cases is extracted from the 18 Load-step results respectively. The temperature of the measuring point gradually increases with time, and because of the forced convection state, the temperature rise rate tends to decrease, until reaching a steady state in the end, when heat and forced cooling temperature get a balance.

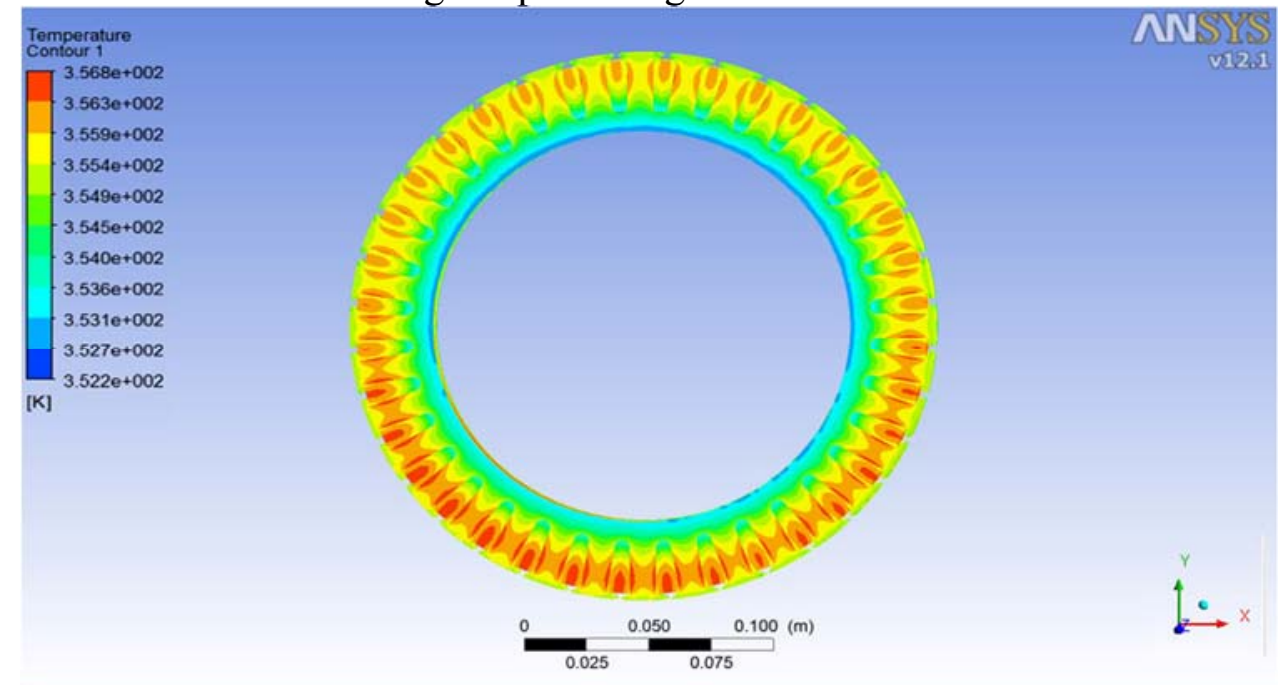

Fig. 4 Radial Temperature Field Distribution of Forced Convection

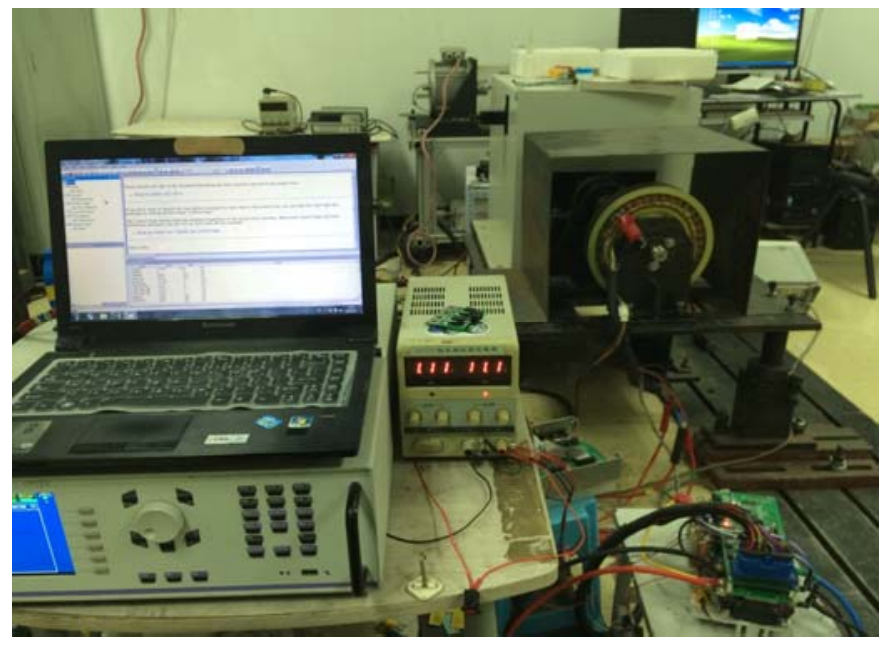

Fig. 5 Experimental System

\section{Experimental Verification}

Natural convection heat transfer cooling state corresponds to the simulation condition. the experimental includes two conditions; the output power of the first case is $1.5 \mathrm{~kW}$, ambient temperature of $17.5^{\circ} \mathrm{C}$; the second discharge conditions is the output power of $1.1 \mathrm{~kW}$, ambient temperature for $18.3^{\circ} \mathrm{C}$. Forced convection cooling and cooling state corresponds to the simulation conditions, the output power of $1.5 \mathrm{~kW}$ discharge conditions, the use of anemometer measured 
cooling wind speed of $2 \mathrm{~m} / \mathrm{s}$, ambient temperature of $20.5^{\circ} \mathrm{C}$. The results of the above three conditions are simulated and shown in Fig. 6.

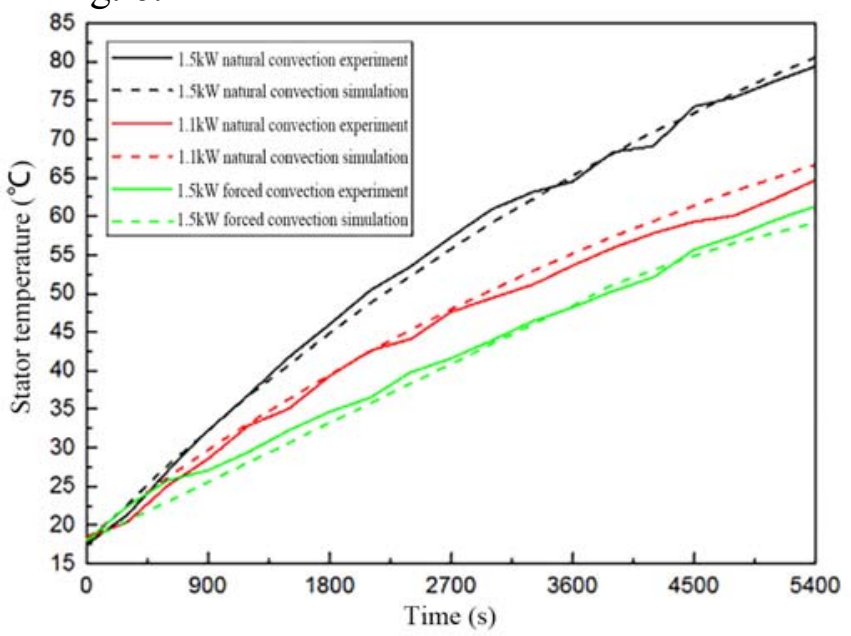

Fig. 6 Comparison of Stator Temperature between Experiments and Simulation Results

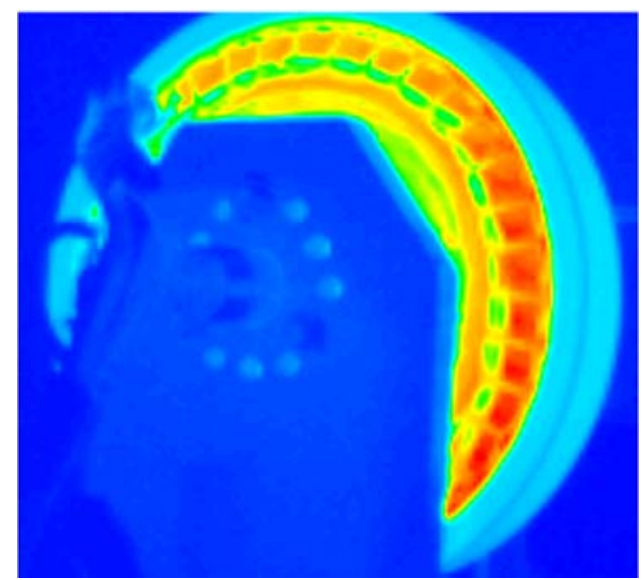

Fig. 7 Motor Temperature Field Shoot by Thermal Imager

To get more intuitive comparisons, the simulation data and experimental data at the end (i.e., 5400s) are listed in Table 4.

Table 4 Temperature comparison between experiments and simulations

\begin{tabular}{c|c|c}
\hline Detection condition & Experimental temperature & Simulation temperature \\
\hline $\begin{array}{l}1.5 \mathrm{~kW} \text { Natural } \\
\text { convection }\end{array}$ & $79.4^{\circ} \mathrm{C}$ & $81.05^{\circ} \mathrm{C}$ \\
\hline $\begin{array}{l}1.1 \mathrm{~kW} \text { Natural } \\
\text { convection }\end{array}$ & $64.7^{\circ} \mathrm{C}$ & $66.67^{\circ} \mathrm{C}$ \\
\hline $\begin{array}{l}1.5 \mathrm{~kW} \text { Forced } \\
\text { convection }\end{array}$ & $61.3^{\circ} \mathrm{C}$ & $59.19^{\circ} \mathrm{C}$ \\
\hline
\end{tabular}

The actual motor temperature field measured by the thermal imager is shown in Fig. 7. It can be seen from Fig. 6 and Table 4 that the experimental data curve and the simulation data curve are basically consistent, the maximum error about $2^{\circ} \mathrm{C}$. The simulation temperature is slightly higher than the experimental temperature, because the actual motor loss is not completely converted into heat. Overall, the simulation results are within the allowable error limits.

It can be seen from Fig. 7 that the actual temperature outside the rotor temperature is very low, almost close to the ambient temperature, so it can be considered as the boundary and can be simulated as consistent. The temperature distribution of the stator and the winding is very similar to the 
simulation result. Therefore, the temperature field distribution of the overall simulation is similar to the observed temperature field distribution, which can support the accuracy of the simulation results.

\section{Conclusion}

In this paper, the calculation of the working current of the permanent magnet in-wheel motor and the working conditions were carried out. The thermal simulation model of the permanent magnet in-wheel motor was established, and the calculation conditions were determined based on the solar vehicle parameters. The three-dimensional model of the motor was established by the Fluent software, and the thermal characteristics of the two models were simulated.

The radial temperature field distribution of the forced convection motor was obtained by simulation calculation. The simulation results were verified by the test experiment. The research results laid the foundation for further thermal design and thermal optimization.

\section{References}

[1] Jinxin Fan, Chengning Zhang, Zhifu Wang, et a1. Thermal Analysis of Permanent Magnet Motor for the Electric Vehicle Application Considering Driving Duty Cycle [J].IEEE TRANSACTIONS ON MAGNETICS, 2010, 46(6):2493-2496.

[2] J.P. Bastos, M.F.R.R. Cabreira, N. et al. A thermal analysis of induction motors using a weak coupled modeling. Magnetics, IEEE Transactions on. March 1997, 33(2):1714-1717

[3] K. Farsane, P. Desevaux, P. K. Panday. Experimental study of the cooling of a closed type electric Motor. Applied Thermal Engineering, 2000, 20: 1321 1334.

[4] L. Kung, U. Bikle, O. Popp, R. Jakoby. Improvement of the cooling performance of symmetrically self-ventilated induction machines in the 2-15 MW range. Electric Machines and Drives Conference, 2001. IEMDC 2001. IEEE International: 673 680.

[5] H. Neudorfer. Hydraulic cooling Three-phase AC motor. Converter Technology \& Electric Traction, 2001, 8(6):34-35

[6] W.M.TONGI, R.Y.TANG, L.A.ZHONG et a1. Water Cooling System Design and Thermal Analysis for Low Speed Permanent Magnet Machines. International Conference on Electrical Machines and Systems, 2011, 20(12):51-54

[7] Wen Zhi-wei, Gu Guo-biao, Wang Hai-feng, Calculation of 3D thermal Field in the Stator of Turbo generator with immersion evaporative cooling system and force inner cooling. Proceedings of The Chinese Society for Electrical Engineering, 2006, 12:133-138.

[8] Anis Dehbi, Evgenii B Rudnyi, Peter van Duijsen. Efficient Electrothermal Simulation of Power Electronics for Hybrid Electric Vehicle [J].IEEE978-1-4244-2128-2/08, 2008:1-7.

[9] Issam Mudawar. TWO-PHASE SPRAY of COOLING HYBRID VEHICLE ELECTRONICS [J]. IEEE Heat Transfer Engineering, 2008, 30(12):1210-1221. 